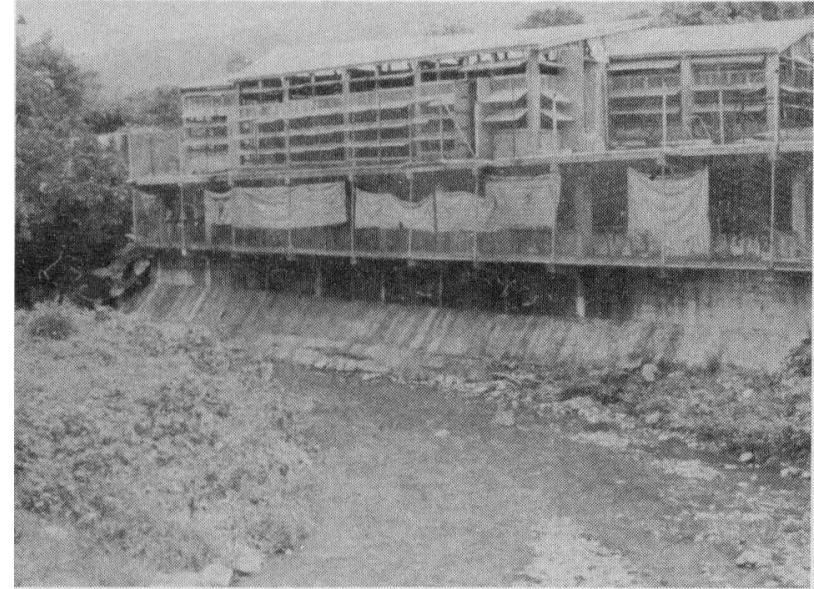

Fig. 1. Streamside farm in Hong Kong's New Territories, with excreta and other effluent still being discharged untreated into the stream.

farmers who, for reasons of space or accessibility, could not comply with the controls.

Under the proposed scheme, a nine-years' programme costing some HK $\$ 265$ millions (about $£ 24$ millions) would provide for the treatment of animal wastes collected from farms, the resulting sludge being disposed of with municipal waste at landfall sites. Farmers would be unable to bear the full cost of the programme, the

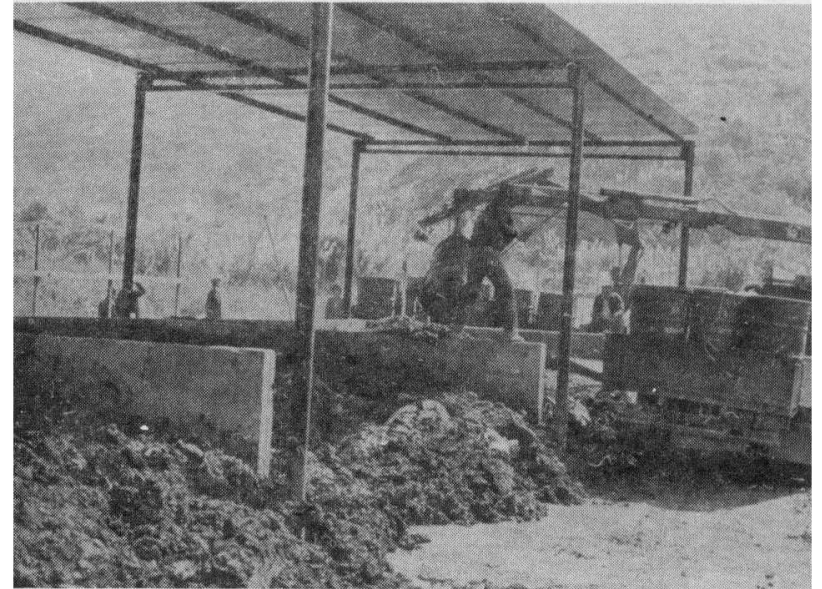

Fig. 2. Composting plant at Ngau Tam Mei, Hong Kong.

consultants have advised, and some financial support, possibly from a special levy, would be essential.

\author{
ROBERT BIDWELL, Director \\ Environmental Resources Limited \\ 79 Baker Street \\ London WIM IAJ \\ England, UK.
}

\title{
Leprosy, Continuing Factor of the Human Environment
}

Leprosy still occurs in more than 70 countries, mainly in Africa and Asia, but also in some South and Central American countries. It is caused by Micobacterium leprae, first described by Gerhard Armaner Hansen of Norway in 1873, and has a long incubation period-generally from three to 10 years. According to WHO estimates, there are between 10 and 11 million leprosy cases in the world, about half of whom have been identified by the health services.

In countries where leprosy occurs, the number of cases does not usually exceed $5 \%$ of the total population. Nevertheless, some four million people are disabled to various degrees as a result of this disease. Their disfigurement causes aversion, resulting in serious psychological and social problems for the leprosy patients and their families.

Many leprosy cases have a benign form and tend to heal spontaneously. But a considerable number of cases, called lepromatous, harbour large numbers of the bacilli and are seriously affected; these cases show a gradual progression of the disease when untreated. They also constitute the principal source of transmission.

The mechanism of transmission of the leprosy Bacterium and the factors which determine the occurrence of the disease in persons infected with it are still unclear. Leprosy is not a hereditary disease, but constitutes a far more serious problem than the sheer number of cases belies, as it involves disabilities, economic loss, and psychological trauma for those affected. Leprosy is, in general, associated with poverty.

Formerly, the basis of leprosy control consisted of the administration of one drug, called Dapsone, which had to be given for many years. Unfortunately in recent years, resistance to Dapsone has become a major problem, and today, WHO recommends the use of combinations of drugs as the basis of therapy. These combinations are more expensive, more complex to administer, and require greater supervision, than did Dapsone. However, the fact that they are far more efficient means that they do not have to be used over such long periods of time, as was the case with Dapsone alone-thus making them more economical in the long run.

All countries where leprosy occurs are now making efforts to introduce this new therapy into their leprosy control programmes. In the past, as a result of prejudice against leprosy, many leprosy control programmes were conducted in a specialized manner. Since the leprosy control strategy is based on early diagnosis and regular treatment, the corresponding activities require full community participation and therefore are to be included first and foremost in the primary health-care (PHC) system.

WHO plays a world-wide role in coordinating, supporting, and stimulating, effective leprosy control programmes within the primary health-care approach. The strategy of control is based on early case-detection and regularly supervised multidrug therapy. All countries where leprosy occurs receive assistance for their leprosy control programmes from many bilateral and voluntary agencies.

An international research network into the Immunology of Leprosy (IMMLEP) and the Chemotherapy of Leprosy (THELEP) has been set up under the United Nations Development Programme/World Bank/WHO Special Programme for Research and Training in Tropical Diseases. The multidrug regimens are an important outcome of this research. The progress in research aimed at producing a leprosy vaccine is also encouraging.

Division of Public Information World Health Organization 1211 Geneva 27 Switzerland. 